\title{
In Search of the Optimum Tariffs Under Third-Degree Price Discrimination
}

\author{
C. W. Yang \\ Clarion University of Pennsylvania \\ S. N. Sohng \\ Clarion University of Pennsylvania \\ B. N. Huang \\ National Chung Cheng University \\ Cindy H. P. Peng \\ National Central University \& Yuda College
}

\begin{abstract}
Tariff literature on third-degree price discrimination remains only lightly explored. The purpose of the paper is to investigate whether there exist optimum tariffs in the presence of different demand elasticities. We explore (i) the case of optimum uniform ad valorem tariff, and (ii) the case of optimum discriminatory ad valorem tariffs. A two-stage optimization approach is used: profit is maximized for a foreign firm in the first stage and importing country's optimum tariff rates are determined under maximization of welfare (sum of consumer surplus and tariff revenue). The result indicates that the optimum tariffs may not exist even with a set

\footnotetext{
*Corresponding address: C. W. Yang, Department of Economics, Clarion University of Pennsylvania Clarion, PA 16214, Tel: +1-814-393-2609, Fax: +1-814-393-1910, E-mail: yang@clarion.edu, S. N. Sohng, Department of Economics, Clarion University of Pennsylvania Clarion, PA 16214, Tel: +1-814-393-2632, Fax: +1-814-393-1910, E-mail: sohng@claron.edu, B. N. Huang, Department of Economics and Center for IADF National, Chung Cheng University Chia-yi, Taiwan, Tel: +886-5272-0411, Fax: +886-52720816, E-mail: ecdbnh@ccu.edu.tw, Cindy Hsiao-ping Peng, Department of Industrial Economics, National Central University, Chung-li, and Yuda College, Mio-li, Taiwan, Tel: +886-3422-6134, Fax: +886-37551285, E-mail: S1444001@yahoo.com.tw @2006-Center for International Economics, Sejong Institution, All Rights Reserved.
} 
of well-behaved linear demand functions. Consequently, computer simulations are needed with cost and demand parameters to ensure better welfare position for home country.

\section{- JEL classifications: F10, F12}

- Key words: Optimum, Discriminatory Tariffs

\section{Introduction}

Enough ink has been spread on third-degree price discrimination since the work by Pigou (1920). Perhaps the most well-known piece is the one by Robinson (1934) in which output and welfare effects were explored. Subsequent work has been advanced by Edwards (1950), Silberberg (1970), Battalio and Ekelund (1972), Yamey (1974), Finn (1974), Greenhut and Ohta (1976), Smith and Formby (1981), Schmalensee (1981), Formby et al. (1982), Varian (1985), Shin et al. (1988), Nahata et al. (1990), Schwartz (1990), Malueg (1993). The application of third-degree price discrimination is widespread even across different continents over various types of commodities (e.g., academic journal of Europe and North America according to Hamaker and Astle (1984)). Nonetheless, the taxation or tariff topic has been much ignored (e.g., Yang, 1993; Cheung, 1998). Yang's work primarily focuses on single taxes within the framework of profit maximization. Recently, Yang et al. (1996) prove that an optimum uniform tariff over $n$ countries must be a convex combination of different discriminatory tariffs with a set of linear demand functions. However, their tariffs are measured in terms of dollar per unit or unit tariffs. Not surprisingly, tariffs of different countries may vary substantially according to domestic production and consumption environments. For instance, average tariff rates on toys were 3.2 per cent, 4.6 per cent, 8 per cent, 4.3 per cent, and 41.6 per cent for Canada, Australia, South Korea, Japan, and China respectively in 2000, 18.2 per cent, 3 per cent, 30.2 per cent, 16 per cent, and 40 per cent for food items, 2.97 per cent, 1.4 per cent, 5 per cent, 1.4 per cent, 24.7 per cent, for jewelry and 4.8 per cent, 7.3 per cent, 7.1 per cent, 2.1 per cent, and 25.8 per cent for automobile. It is to be pointed out that discriminatory tariffs under other imperfect competition (Brander and Spencer, 1984; Hwang and Mai, 1991) begin to receive more attention. For instance, Li et al. (1996) simulated pollution tariffs using the Hwang-Mai model who based their analysis on the Cournot competition. Chou et al (2002) apply the Hwang-Mai model to a multi-country 
pollution tariff coordination scheme: lower tariff for countries with more rigorous anti-pollution standards. Clearly the Cournot models have yielded more empirical applications, for their solution sets incorporate that of traditional mathematical programming model. For example, Yang et al. (2002) proposed and implemented a spatial equilibrium Cournot model with taxes in the framework of linear complementarity programming which admits more sets of solutions than are allowed by nonlinear concave programming. It is long-recognized that nonlinear mathematical programming is a special case of the linear complementarity programming (Cottle, 1972; Irwin and Yang, 1982, 1983). As is to be shown in this paper, the third-degree price discrimination model is cast within a two-stage optimization framework in which the solution of the first stage is fed into the second stage as input before obtaining the optimum tariffs. The filtering procedure may be quite restrictive regarding the optimum tariffs. As a consequence, we employ highly simplified linear demand and cost functions to demonstrate that numerical simulations may well be necessary in the case when optimality is either lacking or not feasible, or being forced to take on corner solutions (zero consumptions for some countries). Given the prevalence of different tariff rates, the purpose of this paper is to investigate the possibility of an optimum ad valorem tariff, which involves changes in both intercept and slope of a demand function. To the best of our knowledge, the topic remains largely unexplored and the result is used to fill a void in the literature. The organization of the paper is as follows. The next section presents optimum uniform ad valorem tariff. Section III discusses the possibility of discriminatory ad valorem tariff. Section IV includes a conclusion.

\section{Optimum Uniform Ad Valorem Tariff}

Consider a demand function for market $i($ for $i=1, \ldots, n) q_{i}=g\left(p_{i}\right)$ in which $q_{i}$ is a monotonically decreasing function of $p_{i}$ so that $p_{i}=f\left(q_{i}\right)$ is uniquely defined. The firm's total cost function is TC such that $T C^{\prime}(q) \geq 0$, i.e., marginal cost is nonnegative. Note that $q=\sum q_{i}$, we use the two-stage optimization procedure in which the firm's after-tariff profit is maximized or

$$
\text { Maximize } \pi=(1-\mu) \sum p_{i} q_{i}-T C(q)
$$

where $\mu$ is the single ad valorem tariff, the first-order condition leads to 


$$
\begin{gathered}
\frac{\partial \pi}{\partial q_{i}}=(1-\mu)\left(p_{i}+q_{i} p_{i}^{\prime}\right)-\frac{\partial T C}{\partial q} \frac{\partial q}{\partial p_{i}}=0 \\
\text { or } \quad(1-\mu) M R_{i}-M C=0
\end{gathered} \quad \forall i \in N
$$

where $\mathrm{N}$ is an integer set, and $\partial q / \partial q_{i}=1$. .

We then solve for $n q_{i}^{\prime} s$ from $n$ first-order conditions. If the solution of $q_{i}^{\prime} s$ exists uniquely, it is a function of $\mu$ and demand function parameters or

$$
q_{i}^{*}=h(\mu, \alpha)
$$

where $\alpha$ is a set of estimated coefficients of demand functions.

The second stage involves the choice of an optimal $\mu$ that maximizes the sum of consumer surplus (CS) and tariff revenue (TR):

$$
\text { Maximize } V=C S+T R
$$

$$
\begin{gathered}
\text { where } C S=\sum\left(\int_{0}^{q_{i}^{*}} p_{i}\left(q_{i}\right) d q_{i}-p_{i} q_{i}^{*}\right) \\
T R=\mu \sum p_{i} q_{i}
\end{gathered}
$$

$q_{i}^{*}=$ optimal output in market $i$ under the single ad valorem tariff.

The first order condition is

$$
\sum \partial \int_{0}^{q_{i}^{*}} p_{i}\left(q_{i}\right) d q_{i} / \partial q_{i} \cdot \frac{\partial q_{i}}{\partial \mu}-\sum p_{i} \frac{\partial q_{i}}{\partial \mu}-\sum q_{i}^{*} \frac{\partial p_{i}}{\partial q_{i}} \frac{\partial q_{i}}{\partial \mu}=0
$$

Since $q_{i}^{\prime} s$ are determined from the first stage, $q_{i}^{*}=h(\mu, \alpha)$ can also be evaluated. Substitute them into (7) and one may solve for an optimal $\mu$ in the case of single ad valorem tariff. However, equation (7) assumes a general functional form whose components are determined from the first-stage optimization. In other words, the values assumed from the first stage can be rather restrictive, and as such one may have only sub-optimal values for the uniform ad valorem tariff. To simplify the calculation, we employ separable linear demand functions for only two markets and a linear total cost function for the firm as shown below:

$$
p_{i}=a_{1}-b_{1} q_{1}=225-0.005 q_{1}
$$




$$
\begin{gathered}
p_{2}=a_{2}-b_{2} q_{2}=125-0.00125 q_{2} \\
T C=c+d\left(q_{1}+q_{2}\right)=2000+25\left(q_{1}+q_{2}\right)
\end{gathered}
$$

The profit-maximizing quantities from the first stage optimization can be shown as

$$
\begin{gathered}
q_{1}^{*}=\frac{a_{1}(1-\mu)-d}{2 b_{1}(1-\mu)} \\
q_{2}^{*}=\frac{a_{2}(1-\mu)-d}{2 b_{2}(1-\mu)}
\end{gathered}
$$

substituting (8) and (9) and $\partial q_{1}{ }^{*} / \partial \mu$ and $\partial q_{2}{ }^{*} / \partial \mu$ into $\partial V / \partial \mu=0$ (or equation (7)),

we obtain

$$
\begin{aligned}
& -\left(a_{1}^{2} b_{2}+a_{2}^{2} b_{1}\right) \mu^{3}+\left(3 a_{1}^{2} b_{1}+3 a_{2}^{2} b_{1}\right) \mu^{2}-\left(3 a_{1}^{2} b_{2}+3 a_{2}^{2} b_{1}+a_{1} b_{2} d\right. \\
& \left.+a_{2} b_{1} d+3 b_{1} d^{2}+3 b_{2} d^{2}\right) \mu+\left(a_{1}^{2} b_{2}+a_{2}^{2} b_{1}-a_{1} b_{2} d-a_{2} b_{2} d\right)=0
\end{aligned}
$$

Evidently, the search for the optimal uniform ad valorem tariff hinges on the solution of this rather complicated polynomial equation of degree three, whose solution (exactly three) characteristics are contained in the well-known De Cartes's theorem regarding the exact number of solutions and the sign test for positive (negative)-valued solutions.

A simulation by a nonlinear optimization GINO (Liebman et al. 1986) indicates the optimum uniform ad valorem tariff of 1.212: obviously an infeasible one (it exceeds 100 per cent). The other two solutions are a pair of complex conjugates, irrelevant for our analysis. Note that lacking the optimum solution does not imply a sub-optimal solution does not exist. For this reason, we simulated the tariff rate from 0 per cent to 90 per cent with an increment of 10 percentage points and evaluate the welfare in terms of $C S+T R$. Results are reported in Table 1.

An examination of Table 1 indicates the sum of $C S$ and $T R$ is maximized approximately at $\mu=60$ per cent, indicating a rather stiff tariff rate. Of course, parameters of the demand and cost functions are arbitrarily selected, one should not assign too much empirical relevance to the simulated solution. In addition, one must bear in mind that the producer and consumers may not reside in the same country, hence 
Table 1. Welfare under Uniform Ad Valorem Tariff

\begin{tabular}{cccccc}
\hline$\mu$ & 0 & 0.1 & 0.2 & 0.3 & 0.4 \\
\hline$C S+T R$ & $2,000,000$ & $2,463,965$ & $2,899,804$ & $3,295,169$ & $3,623,611$ \\
$\mu$ & 0.5 & 0.6 & 0.7 & 0.8 & 0.9 \\
$C S+T R$ & $3,843,749$ & $3,858,593$ & $3,419,444$ & $1,649,999$ & 0 \\
\hline
\end{tabular}

the summation of $\pi$ and $C S$ and $T R$, unlike welfare measurement within an economy, does not have much relevance. The crux of the matter is that the optimum uniform ad valorem tariff may well not exist even in the case of simple demand and cost functions for two markets. A simulation is needed to ferret out sub-optimal values.

\section{The Optimal Discriminatory Tariff}

Consider a set of discriminatory tariff $\mu_{i}$ imposed in the $i$ the market of a region. The after-tariff profit function is therefore

$$
\pi=n \sum_{i=1}^{n}\left(1-\mu_{i}\right) p_{i} q_{i}-T C(q)
$$

Profit-maximization of (11) with respect to $q=\left(q_{1} \ldots q_{n}\right)$ leads to

$$
\frac{\partial \pi}{\partial q_{i}}=\left(1-\mu_{i}\right) \cdot\left(p_{i}+q_{i}+p_{i}^{\prime}\right)-T C^{\prime}(q)=0
$$

for all $i \in N$. There are $n$ such equations for $q=\left(q_{1}^{*} \ldots q_{n}^{*}\right)$. Assuming a unique solution set exists over $R_{+}^{n}$, we can express $q_{i}^{*}=k(\beta, \mu)$ where $\beta$ is a vector of estimated demand function parameters and $\mu=\left(\mu_{1} \ldots \mu_{n}\right)$. The objective function of the second-stage optimization is the sum of consumer surplus and tariff revenue $(V=C S+T R)$ or

$$
\text { Maximize } V=C S+T R=\sum\left(\int_{0}^{q_{1}^{*}} p_{i} d q_{i}-p_{i}^{*} q_{i}^{*}\right)+\sum \mu_{i} p_{i}^{*} q_{i}^{*}
$$

Again the first-order condition yields immediately.

$$
\frac{\partial V}{\partial \mu_{i}}=\frac{\partial\left(\int_{o}^{p_{1}^{*}} p_{i}\right)}{\partial q_{i}} \cdot\left(\frac{\partial q_{i}}{\partial \mu_{i}}\right)-\left(\frac{\partial p_{i}^{*} q_{i}^{*}}{\partial \mu_{i}}\right)+p_{i}^{*} q_{i}^{*}+\mu_{i} p_{i}^{*}\left(\frac{\partial q_{i}^{*}}{\partial \mu_{i}}\right)+\mu_{i} q_{i}^{*} p_{i}^{\prime}\left(\frac{\partial q_{i}^{*}}{\partial \mu_{i}}\right)=0
$$


for all $i \in N$

There are $n$ such equilibrium conditions. Substituting $q_{i}^{*}=k(\mu, \beta)$ and $\partial q_{i}{ }^{*} / \partial \mu_{i}^{*}$ into (14), we can readily obtain a system of $n$ nonlinear equations. While the existence of the solution rests in the domain of the fixed point theorem, it generally is difficult to calculate a set of global optimal solution especially when $n$ is large. With the identical linear separable demand and cost functions, we obtain the optimum quantity for each market:

$$
\begin{aligned}
& q_{1}^{*}=\frac{a_{1}\left(1-\mu_{1}\right)-d}{2 b_{1}\left(1-\mu_{1}\right)} \\
& q_{2}^{*}=\frac{a_{2}\left(1-\mu_{2}\right)-d}{2 b_{2}\left(1-\mu_{2}\right)}
\end{aligned}
$$

substituting (15), (16) and $\partial q_{i}^{*} / \partial \mu_{i}^{*}$ into (14) and rearranging leads to

$$
\frac{\partial V}{\partial \mu_{1}}=\frac{1}{4 b_{2}\left(1-\mu_{1}\right)^{3}}\left[-a_{1} d\left(1-\mu_{1}\right)+d^{2}+a_{1}^{2}\left(1-\mu_{1}\right)^{3}-d^{2}\left(1-\mu_{1}\right)-2 \mu_{1} d^{2}\right]=0
$$

which produces the polynomial equation of degree 3 or

$$
a_{1}^{2} \mu_{1}^{3}-3 a_{1}^{2} \mu_{1}^{2}+\left(3 a_{1}^{2}+a_{1} d+d^{2}\right) \mu_{1}+\left(-a_{1}^{2}+a_{1} d\right)=0
$$

in which $\left(a_{1}, a_{2}\right)$ and $\left(b_{1}, b_{2}\right)$, denote intercepts and slopes of the two linear demand functions: $\mathrm{c}$ and $\mathrm{d}$ are intercept and slope of the cost function; $\mu_{1} \mu_{2}$ represent discriminatory tariff rates in two consumption countries.

Following exactly the same procedure, we obtain the following polynomial equation for market 2 :

$$
a_{2}^{2} \mu_{2}^{3}-3 a_{2}^{2} \mu_{2}^{2}+\left(3 a_{2}^{2}+a_{2} d+d^{2}\right) \mu_{2}+\left(-a_{2}^{2}+a_{2} d\right)=0
$$

In this simplified example, we find the optimal discriminatory tariffs are $\mu_{1}=1.341$ and $\mu_{2}=1.266$. The other solutions are complex conjugates and hence ignored. Since lacking a global solution does not translate into giving up the 
Table 2. The Welfare under Discriminatory Tariff

\begin{tabular}{ccccccc}
\hline & $\mu_{2}$ & 0.1 & 0.3 & 0.5 & 0.7 & 0.8 \\
\hline$\mu_{1}$ & & & & & & \\
\hline 0.1 & $2,463,965$ & $2,878,252$ & $3,211,033$ & $3,272,838$ & $2,892,282$ \\
0.3 & $2,879,884$ & $3,294,132$ & $3,626,912$ & $3,688,718$ & $3,308,162$ \\
0.5 & $3,096,676$ & $3,510,967$ & $3,843,748$ & $3,905,553$ & $3,524,999$ \\
0.7 & $2,610,571$ & $3,024,858$ & $3,357,638$ & $3,419,447$ & $3,038,888$ \\
0.8 & $1,221,682$ & $* 1,635,969$ & $* 1,968,750$ & $* 2,030,555$ & $* 1,649,999$ \\
\hline
\end{tabular}

*denotes $q_{1}^{*}$, therefore a corner solution

search, we employ a simulation of 25 computer runs with $\mu_{i}=0.1,0.3,0.5,0.7$ and 0.8 via GINO to obtain the welfare measure $(C S+T R)$. Note that we do not raise the tariff to 0.9 where $q_{i}^{*}=0$ for both markets. The results are reported in Table 2 .

An inspection of Table 2 reveals readily that locally optimal pair of discriminatory tariffs lies around $\left(\mu_{1}=0.5, \mu_{2}=0.7\right)$. Note that numerical values along the diagonal in Table 2 are the welfare measure under uniform tariffs. Clearly it needs no mathematical proof to show that uniform tariff taxation cannot be superior to the discriminatory one since it is only a subset of the latter. Note that our simulation is based on two arbitrary chosen linear demand and a simplified linear cost function. As such, tariff rates between 50 per cent and 70 per cent are not empirically relevant. We must be on our guard, against the possibility of such prohibitive rates for they are politically infeasible, should such rates appear as optimum solution. However, empirical estimations of the model remain an interesting topic for future research.

\section{The Optimal Discriminatory Tariff with a Fixed Tariff Revenue}

More often than not, a government policy is set to meet a predetermined level of tariff revenue while maximizing the consumers' welfare (consumer surplus). The first-stage optimization is the same as that in the previous section or

$$
\text { maximize } \pi=\sum_{i=1}^{n}\left(1-\mu_{i}\right) p_{i} q_{i}-T C(q)
$$

with the resulting optimal quantity for $n=2$ (linear case):

$$
q_{1}^{*}=\frac{a_{1}\left(1-\mu_{1}\right)-d}{2 b_{1}\left(1-\mu_{1}\right)}
$$




$$
q_{2}^{*}=\frac{a_{2}\left(1-\mu_{2}\right)-d}{2 b_{2}\left(1-\mu_{2}\right)}
$$

The second-stage optimization procedure can be cast in the following:

$$
\begin{gathered}
\text { Maximize } C S=\sum \int_{0}^{q_{i}^{*}} P_{i} d q_{i}-P_{i}^{*} q_{i}^{*} \\
\text { Subject to } \sum \mu_{i} P_{i} q_{i}=R_{o}
\end{gathered}
$$

The Lagrange function $L$ and its first-order condition for the linear case $(\mathrm{n}=2)$ can be shown as $L=C S+\lambda\left(R_{o}-\sum \mu_{i} P_{i} q_{i}\right)$

$$
\begin{aligned}
& \frac{\partial L}{\partial \mu_{1}}=b_{1} q_{1} \frac{\partial q_{1}}{\partial \mu_{1}}+\lambda\left[-\left(a_{1} q_{1}-b_{1} q_{1}^{2}\right)-\mu_{1}\left(a_{1}-2 b_{1} q_{1}\right) \frac{\partial q_{1}}{\partial \mu_{1}}\right]=0 \\
& \frac{\partial L}{\partial \mu_{2}}=b_{2} q_{2} \frac{\partial q_{2}}{\partial \mu_{2}}+\lambda\left[-\left(a_{2} q_{2}-b_{2} q_{2}^{2}\right)-\mu_{2}\left(a_{2}-2 b_{2} q_{2}\right) \frac{\partial q_{2}}{\partial \mu_{2}}\right]=0 \\
& \frac{\partial L}{\partial \lambda}=R_{o}-\mu_{1}\left(a_{1} q_{1}-b_{1} q_{1}^{2}\right)-\mu_{2}\left(a_{2} q_{2}-b_{2} q_{2}^{2}\right)=0
\end{aligned}
$$

Substituting $\frac{\partial q_{1}^{*}}{\partial \mu_{1}}$ and $\frac{\partial q_{2}^{*}}{\partial \mu_{2}}$ and $q_{1}^{*}, q_{2}^{*}$ into (25) and (26), we have

$$
-a_{1}\left(1-\mu_{1}\right) d+d^{2}+\lambda\left[-a_{1}^{2}\left(1-\mu_{1}\right)^{3}+d^{2}\left(1-\mu_{1}\right)+2 \mu_{1} d^{2}\right]=0
$$

since $4 b_{1}\left(1-\mu_{1}\right)^{3} \neq 0$ and

$$
-a_{2}\left(1-\mu_{2}\right) d+d^{2}+\lambda\left[-a_{2}^{2}\left(1-\mu_{2}\right)^{3}+d^{2}\left(1-\mu_{2}\right)+2 \mu_{2} d^{2}\right]=0
$$

since $4 b_{2}\left(1-\mu_{2}\right)^{3} \neq 0$.

From (28) it can be shown

$$
\lambda=\frac{-a_{1}\left(1-\mu_{1}\right) d+d^{2}}{a_{1}^{2}\left(1-\mu_{1}\right)^{3}-d^{2}\left(1-\mu_{1}\right)-2 \mu_{1} d^{2}}
$$

where $\lambda$ is the Lagrange multiplier. 
Likewise from (29), we have

$$
\lambda=\frac{-a_{2}\left(1-\mu_{2}\right) d+d^{2}}{a_{2}^{2}\left(1-\mu_{2}\right)^{3}-d^{2}\left(1-\mu_{2}\right)-2 \mu_{2} d^{2}}
$$

Equating (30) to (31) yields readily

$$
\frac{-a_{1}\left(1-\mu_{1}\right) d+d^{2}}{a_{1}^{2}\left(1-\mu_{1}\right)^{3}-d^{2}\left(1-\mu_{1}\right)-2 \mu_{1} d^{2}}=\frac{-a_{2}\left(1-\mu_{2}\right) d+d^{2}}{a_{2}^{2}\left(1-\mu_{2}\right)^{3}-d^{2}\left(1-\mu_{2}\right)-2 \mu_{2} d^{2}}
$$

or

$$
\begin{aligned}
& -a_{1} a_{2}^{2}\left(1-\mu_{1}\right)\left(1-\mu_{2}\right)^{3}-a_{2} a_{1}^{2}\left(1-\mu_{2}\right)\left(1-\mu_{1}\right)^{3} \\
& +d^{2}\left(a_{1}-a_{2}\right)\left(1-\mu_{1}\right)\left(1-\mu_{2}\right)+2 d^{2}\left[a_{1} \mu_{2}\left(1-\mu_{1}\right)\right. \\
& \left.-a_{2} \mu_{1}\left(1-\mu_{2}\right)\right]+d\left[\left(-a_{1}^{2}\left(1-\mu_{1}\right)^{3}\right)+a_{2}^{2}\left(1-\mu_{2}\right)^{3}\right] \\
& +d^{3}\left(\mu_{1}-\mu_{2}\right)=0
\end{aligned}
$$

The polynomial equation coupled with equation (29) can be quite involved (negative solutions) and as such we simulate the discriminatory optimal tariff scheme by varying $\mu_{1}$ and $\mu_{2}$ with an increment of 0.1 and setting $R_{\mathrm{o}}=500,000$. The result is reported in Table 3. It is to be noted that the lower part of the table (with $*$ ) indicates a corner solution in which $q_{2}=0$ while the upper part (with $* *$ ) represents cases of $\mathrm{q}_{1}=0$. These corner solutions are not considered in the above optimum conditions in which we assume positive quantities. An examination points to the direction of $\mu_{1}=\mu_{2}=0.1$ : the lowest tariff rate which maximizes consumers surplus while meeting the target of the tariff revenue of 500,000 in our simulation. It speaks to the fact that lower tariff rates are consistent with the consumers' welfare objective: lower prices and greater amount of consumer surplus. The result of the simulation carries an important message: direct optimization in third-degree price discrimination model may well not yield a feasible solution. For a given set of demand and cost estimates, computer simulations, which produce local optimal solutions, seem to serve better purpose than does the direct two-stage optimization method. In the wake of rising regional economic integration in which reciprocal tariffs are more likely to prevail, a low uniform tariff is preferred. Outside the region, however, a set of discriminatory tariffs can be calculated for interregional policy evaluations. In a nutshell, as this paper has indicated, traditional optimization techniques may not be appropriate 
Table 3. Consumer Surplus Under Discriminatory Tariff With a Fixed Tariff Revenue

\begin{tabular}{rrrrrrrrrr}
\hline$\mu_{1}$ & \multirow{2}{*}{0.1} & 0.2 & 0.3 & 0.4 & 0.5 & 0.6 & 0.7 & 0.8 & 0.9 \\
\hline 0.1 & $1,798,991$ & $1,246,442$ & $1,319,678$ & $1,379,762$ & $1,405,288$ & $1,422,018$ & $1,433,675$ & $1,442,298$ & $1,448,936$ \\
0.2 & & & & $* *$ & $* *$ & $* *$ & $* *$ & $* *$ & $* *$ \\
& $1,441,410$ & 833,158 & 907,665 & 977,457 & 977,457 & 977,457 & 977,457 & 977,457 & 977,457 \\
0.3 & & & & $* *$ & $* *$ & $* *$ & $* *$ & $* *$ & $* *$ \\
& $1,449,062$ & $1,236,498$ & 718,566 & 656,855 & 656,855 & 656,855 & 656,855 & 656,855 & 656,855 \\
0.4 & $1,458,377$ & $1,340,593$ & $*$ & $*$ & $* *$ & $* *$ & $* *$ & $* *$ & $* *$ \\
& & & 718,566 & 605,371 & 579,385 & 579,385 & 579,385 & 579,385 & 579,385 \\
0.5 & & $*$ & $*$ & $*$ & $* *$ & $* *$ & $* *$ & $* *$ \\
& $1,465,216$ & $1,385,916$ & 718,566 & 605,371 & 562,499 & 548,058 & 548,058 & 548,058 & 548,058 \\
0.6 & & & $*$ & $*$ & $*$ & $*$ & $* *$ & $* *$ & $* *$ \\
& $1,470,229$ & $1,411,199$ & 718,566 & 605,371 & 562,499 & 541,457 & 532,243 & 532,243 & 532,243 \\
0.7 & & & $*$ & $*$ & $*$ & $*$ & $*$ & & $* *$ \\
& $1,474,017$ & $1,427,320$ & 718,566 & 605,371 & 562,499 & 541,457 & 529,534 & 517,848 & 523,138 \\
0.8 & & & $*$ & $*$ & $*$ & $*$ & $*$ & $*$ & \\
& $1,476,966$ & $1,438,490$ & 718,566 & 605,371 & 562,499 & 541,457 & 529,534 & 522,127 & 508,860 \\
0.9 & & & $*$ & $*$ & $*$ & $*$ & $*$ & $*$ & $*$ \\
& $1,479,322$ & $1,446,685$ & 718,566 & 605,371 & 562,499 & 541,457 & 529,534 & 522,127 & 517,185 \\
\hline
\end{tabular}

when the optimum tariffs are considered either prohibitively high or being forced to take on corner solutions. Or worse, they simply do not exist.

\section{Conclusion}

In this paper, we have shown that the optimal ad valorem tariffs under thirddegree price discrimination could be quite illusive. In the case of uniform tariff with linear separable demand and linear cost functions for just two markets, the search for the optimality is contained in De Carte's theorems regarding existence and characteristics of solutions. In the cases of discriminatory tariffs, the existence of optimal tariff is housed in the domain of fixed point theorem regarding a system of general nonlinear equations. With the same parameters used in our simulations, it is found that globally optimal tariffs do not exist in these cases. It is to be pointed out that linear functions are used to illustrate the potential lack of the solution, rather than its existence. To this end, computer simulations are employed to search for sub-optimal values even in the case of linear separable demand and cost functions for $n=2$. Clearly, an optimum uniform tariff is only a special case of optimum discriminatory tariffs. One can also eliminate prohibitively high tariffs for being infeasible (corner solution). Within the economically integrated region (e.g., NAFTA, EU, ASEAN), one can concentrate on the size of consumer surplus in 
addition to a fixed tariff revenue on the diagonal line (uniform tariff). Our simulation reveals a low tariff rate (but not zero) is preferred. For trades outside the region, the entire table barring the corner solutions needs to be evaluated in terms of consumer surplus along with a target tariff revenue for each country.

Received 14 September 2001, Accepted 14 September 2005

\section{References}

Brander, J.A., and Spencer, B. J. (1984) "Trade Welfare: Tariffs and Cartels," Journal of International Economics, 16, 227-242.

Battalio, R.C., and Robert B. Ekelund, Jr., "Output Change Under Third-Degree Price Discrimination," Southern Economic Journal, (October 1972): 285-90.

Chou, D. Y., H.W. Cheng, and C. W. Yang (2002) "Optimal Environmental and Trade Policies: A Case of Imperfect Competition and Cross-Border Pollution," Agriculture and Economics, 29, 55-74.

Cottle, R. W. (1972) "Monotone Solution of the Parametric Linear Complementarity Problem," Mathematical Program, 3, 210-224.

Edwards, Edgar O., "The Analysis of Output under Discrimination," Econometrica, (April 1950): 163-72.

Finn, Thomas J., "The Quantity of Output in Simple Monopoly and Discriminating Monopoly," Southern Economic Journal, (October 1974): 239-43.

Formby, John P., S. K. Layson, and W. James Smith, "The Law of Demand, Positive Sloping Marginal Revenue, and Multiple Profit Equilibria," Economic Inquiry, (April 1982): 303-11.

Greenhut Melvin L. and Hiroshi Ohta, “Joan Robinson's Criterion for Deciding Whether Market Discrimination Reduces Output," Economic Journal, (March 1976): 96-97.

Hamaker, C. and Astle D. (1984) "Recent Pricing Patterns in British Journal Publishing," Library Acquisition: Practice and Theory, 8(4), 225-32.

Hwang, H., and C.C. Mai (1991) "Optimum Discriminatory Tariffs Under Oligopolistic Competition," Canadian Journal of Economics, 24, 693-702.

Irwin, C. L., and C. W. Yang (1982) "Iteration and Sensitivity for a Spatial Equilibrium Model With Linear Supply and Demand Functions," Operations Research, 30, 319335.

and C. W. Yang (1983) "Iteration and Sensitivity for a Non-Linear Spatial Equilibrium Problem," Lecture Notes in Pure and Applied Mathematics, 85, 91-107.

Li, J., D. B. Means, L. S. Chen, and H. P. Peng (1996) "A Cournot Competition Model With the Uniform Pollution Tariff: An Application to NAFTA," International Journal of Environment and Pollution, 6, 50-56.

Liebman, J., Lasdon, L. Schrage, L and A. Waren, Modeling and Optimization with GINO (Palo Alto, CA.: The Scientific Press, 1986). 
Malueg, D. (1993) "Bounding the Welfare Effects of Third-Degree Price Discrimination," American Economic Review, 83(4), 1011-1021.

Nahata, Babu, Kazysztof Ostaszewski, and P. K. Sahoo, "Direction of Price Changes in Third-Degree Price Discrimination," American Economic Review, (December 1990): 1254-58.

Pigou, Arthur C., The Economics of Welfare, 1st edition, (London: Macmillan, 1920).

Robinson, Joan, The Economics of Imperfect Competition, (London: Macmillan, 1934).

Schmalensee, Richard, "Output and Welfare Implications of Monopolistic Third-Degree Discrimination," The American Economic Review, (March 1981): 242-47.

Schwartz, Marius, "Third-Degree Price Discrimination and Output: Generalizing a Welfare Result," American Economic Review, (December 1990): 1259-62.

Shih, Jun-ji, Chao-cheng Mai and Jung-chao Liu, "A General Analysis of the Output Effect Under Third-Degree Price Discrimination," Economic Journal, (March 1988): 149-58.

Silberberg, Eugene, "Output Under Discriminatory Monopoly," Southern Economic Journal, (July 1970): 84-87.

Smith, W. James and John P. Formby, "Output Changes Under Third-Degree Price Discrimination: A Reexamination," Southern Economic Journal, (July 1981): 164-71.

Varian, Hal R., "Price Discrimination and Social Welfare," The American Economic Review, (September 1985): 870-75.

Yamey, B.S., "Monopolistic Price Discrimination and Economic Welfare," Journal of Law and Economics, (October 1974): 377-80.

Yang, C.W. (1993) "Taxation and the Output and Welfare of Third-Degree Price Discrimination," Southern Economic Journal, 59(3), 371-384.

, M. J. Hwang, and S. N. Sohng (2002) "The Cournot Competition in the Spatial Equilibrium Model," Energy Economics, 24, 139-154.

Yang, C.W. Peng, H. P. and J. F. Li (1996) "The Optimum Uniform and Discriminatory Taxes or Tariffs of Third-Degree Price Discrimination," International Review of Economics and Finance, 5(1), 77-84. 